\title{
PENCIPTAAN MOTION COMIC WAYANG BEBER JAKA KEMBANG KUNING
}

\author{
Indiria Maharsi \\ Dosen Program Studi Desain Komunikasi Visual \\ Jurusan Desain, Fakultas Seni Rupa, Institut Seni Indonesia Yogyakarta \\ indiriamaharsi1@gmail.com
}

\begin{abstract}
Jaka Kembang Kuning is one of the acts performed in Wayang Beber Pacitan. It tells about Dewi Sekartaji leaving her kingdom, Kediri. The story is downright attractive. However, people are no longer in enthusiasm to enjoy this performing art. It is due to the more rich performance choices offered to them. The bad condition of the wayang (puppets) worsens this condition. Reperforming Jaka Kembang Kuning in a new mode of presentation is an effort to revitalize Wayang Beber Pacitan. One of the new promising media that can be used is motion comic. It is highly suggested that Indonesian comic is rooted in wayang beber. Motion comic as a brand new way to present comic recently gains popularity among comic lovers, the youth in particular. It is hoped that the young generation will be persuaded to enjoy the performance by the animation and the audio-visual used in it. In turn, this positive impact will result in the preservation of wayang beber as a cultural heritage of Indonesia.
\end{abstract}

Keywords: Wayang Beber Pacitan, Jaka Kembang Kuning, comic, motion comic.

\section{PENDAHULUAN}

Motion Comic adalah gabungan antara komik dan animasi terbatas atau limited animation. Animasi sederhana ini biasanya hanya permainan layer per layer saja dan geraknya juga tidak terlalu banyak. Gerak ke kiri atau ke kanan, zoom in atau zoom out. Contohnya adalah Motion Comic yang dibuat DC Comic's dengan Watchmen dan Peanuts kemudian Marvel dengan Spider Woman (Maharsi, 2011: 161). Motion Comic sebetulnya muncul karena perkembangan tekhnologi digital yang semakin maju dan berkembang. Terlebih lagi saat ini telah hadir begitu banyak software komputer yang mampu mewujudkan konsep presentasi yang makin kreatif dan beragam di dunia cyberspace. Munculnya website semakin membuka peluang karya-karya komik untuk mampu secara cepat tersebar keseluruh dunia dengan sangat mudahnya. Sehingga dengan demikian basis digital dalam proses pembuatan komik ataupun media show offnya menjadi semacam keharusan bagi para kreator untuk memakainya sebagai alat baru dalam proses berkarya.

Animasi sederhana yang terdapat dalam Motion Comic seperti ini mirip sekali dengan 2D Hybrid Animation, yaitu animasi yang menggunakan penggabungan gambar demi gambar secara manual melalui media kertas dan kemudian gambar-gambar tersebut disatukan dengan tekhnik digital (komputer) dalam proses geraknya (Gumelar, 2004: 7). Terobosan baru basis media komik dalam Motion Comic yang berbasis digital ini menyebabkan semakin maraklah perkembangan komik saat ini.

Motion Comic sebagai bentuk media baru dalam komik menjadi popular karena 
kolaborasinya dengan dunia animasi dan multimedia. Tidak seperti komik konvensional yang berujud fisik buku atau dalam selembar kertas, Motion Comic menawarkan kebaruan dengan memberikan sentuhan limited animation, narasi maupun backsound dalam presentasinya kehadapan para pembaca. Animasi dan suara tersebut membawa suasana yang berbeda dan unik kepada pembaca. Disamping itu Motion Comic sangat mudah diakses karena menggunakan world wide web dalam presentasinya. Intinya cara presentasi baru di dunia komik dalam wujud Motion Comic menjadi semacam alternatif baru bagi pengembangan komik secara khusus. Terlebih lagi komik ini pada saat sekarang banyak digemari oleh para pembaca karena kemudahan akses dan kebaruan cara presentasinya.

\section{WAYANG BEBER PACITAN}

Wayang Beber Pacitan berbentuk lukisan atau gambar diatas kertas dan berwarna. Karakter muka sama seperti wayang kulit purwa namun kedua matanya terlihat, jadi terkesan tiga dimensional. Seperti halnya Wayang Beber Wonosari, Wayang Beber Pacitan ini digunakan juga untuk acara ruwatan, kaulan atau nadar. Semua itu dilakukan agar terhindar dari malapetaka atau kesukaran misalnya sakit, susah melahirkan dan lain sebagianya (Achmad, 1990: 255). Sehingga disini jelas sekali peran dalang sebagai tokoh spiritual yang sangat disegani masyarakat di tempat tersebut. Demikian juga dengan Wayang Bebernya, bisa dikatakan sebagai benda pusaka yang sangat bertuah mampu memberikan kontribusi yang positif secara spiritual bagi permasalahan yang menimpa masyarakat disekitar wilayah tersebut.

Inti cerita dari lakon Cerita Panji dalam Wayang Beber Pacitan ini adalah mengenai hilangnya Dewi Sekartaji dari Kediri yang kemudian dicari oleh Panji Asmarabangun yang menyamar sebagai Jaka Kembang Kuning. Pada akhirnya setelah melewati berbagai peristiwa maka Dewi Sekartaji akhirnya ditemukan dan dikawinkan dengan Panji Asmarabangun (Achmad, 1990: 260). Cerita Panji tersebut berbeda dengan Wayang Beber Gelaran Wonosari. Perbedaan yang lain, jika Wayang Beber Wonosari terbagi dalam empat gulungan maka untuk Wayang Beber Pacitan ini terbagi menjadi enam gulung kertas, tiap-tiap gulung berisi empat jagong atau adegan dengan cerita "Jaka Kembang Kuning". Menurut R.M. Sayid, lakon Jaka Kembang Kuning merupakan lakon kiasan tentang sesuatu yang benarbenar terjadi. Menurutnya lakon ini merupakan kiasan dari sebuah peristiwa yang terjadi yang pada saat Kerajaan Mataram Islam ketika pemerintahan Susuhunan Amangkurat I, yaitu ketika Trunojoyo berhasil merebut Kerajaan Mataram di Plered. (Pustaka Wisata Budaya, 1981: 45).

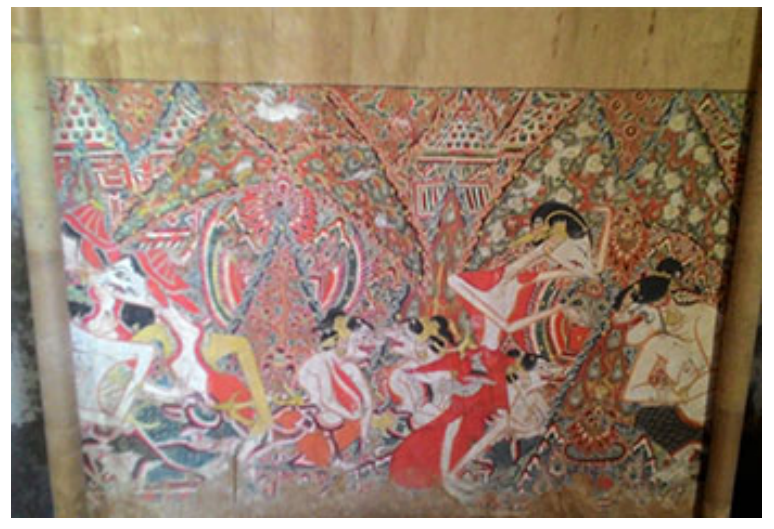

Gambar 1 Wayang Beber Pacitan 
Cerita Wayang Beber Pacitan lakon Jaka Kembang Kuning tersebut sangat menarik, namun faktanya pada saat ini Wayang Beber Pacitan dalam kondisi tidak baik. Beberapa gulungan sudah banyak bagian yang sobek, apalagi pada bagian atas dan bawah kertas. Selain sobek ada juga beberapa warna yang telah hilang atau pudar karena termakan usia. Sehingga agar tetap lestari maka memerlukan kehati-hatian merawat sekaligus ketika membuka wayang tersebut jika dipagelarkan. Terlebih lagi bila pada saat menggulung dan membuka pada saat pagelaran dilakukan, jika tidak pelan ataupun hati-hati maka kemungkinan besar kerusakan wayang tersebut akan bertambah. Disamping itu pagelaran Wayang Beber Pacitan saat ini jarang sekali diadakan, bahkan mungkin dalam jangka waktu satu tahun kadang belum tentu ada pagelaran wayang ini.

\section{MOTION COMIC WAYANG BEBER JAKA KEMBANG KUNING}

Komik yang demikian populer pada saat ini tersebut jika dilihat dari sisi sejarah ternyata ditemukan fakta yang menarik karena terkait dengan hasil karya asli bangsa Indonesia sendiri pada jaman dahulu. Karena jika ditilik dari sejarahnya maka sebetulnya antara komik dan Wayang Beber memiliki hubungan satu sama lain, mengingat bahwa disinyalir Wayang Beber merupakan cikal bakal dari komik. Pernyataan ini disampaikan oleh Dr. Marcel Bonneff dalam bukunya yang berjudul Les Bandes Dessinees Indonesiennes, sebuah buku yang berdasarkan hasil penelitian untuk disertasinya pada tahun 1972. Di dalam buku yang terbit tahun 1976 tersebut secara tegas dikatakan bahwa
Wayang Beber menampilkan tipe penceritaan dengan sarana gambar yang dapat dianggap sebagai cikal bakal komik (1998:19). Dengan demikian ternyata ada artefak budaya lokal Indonesia yang mencatat akan kehadiran sebuah karya besar bangsa sendiri yang sejajar dengan karya bangsa lain. Bahwa merunut sejarah Indonesia ternyata bahasa keindahan yang dipakai nenek moyang dalam merepresentasikan cerita ataupun ide sudah memakai medium komik dalam representasinya. Dalam perkembangannya, segala macam hal yang muncul dalam ranah seni rupa dipetakan dan ditekstualkan dalam berbagai macam pengertian. Pengertianpengertian itupun mengacu kepada artifakartifak peninggalan budaya yang sudah ada, entah itu pengertian komik dari Scot McClod ataupun Will Eisner. Namun intinya, ternyata bangsa Indonesia sudah memakai medium komik ini sejak lama dalam bentuk wayang beber.

Dari pemaparan diatas secara sangat jelas sekali terlihat bahwa antara wayang beber dan komik terdapat hubungan yang sangat erat sekali. Berkaitan dan berhubungan satu sama lain, berkelindan dalam berbagai aspek yang termuat di dalamnya. Terlebih lagi jika kita melihat kembali komik modern maka terlihat bahwa komik modern merupakan sebuah media yang saat ini sangat populer dan pantas diperhitungkan dalam ranah seni rupa. Terlebih lagi ternyata perkembangan komik di Indonesia saat ini sudah cukup menggembirakan baik jika dilihat dari banyak munculnya buku-buku komik karya komikus lokal maupun buku teks yang mengupas tentang komik, meskipun laju perjalanannya masih agak lambat karena belum banyak elemen masyarakat yang terjun dan berperan 
aktif baik secara secara mental, finansial dalam rangka untuk mengangkat citra maupun kehidupan komik Indonesia agar sejajar atau bahkan lebih tinggi dari komik yang berkembang di negara lain seperti Amerika, Jepang, Eropa maupun Korea. Terlebih lagi faktanya hegemoni budaya juga terasakan benar di media komik ini. Hal ini bisa dlihat dari banyaknya generasi muda yang memakai gaya ilustrasi komik dengan mengacu gaya dari luar seperti gaya deformatif idealnya Amerika maupun gaya mata besarnya Manga. Sehingga ciri lokal yang seharusnya dipakai para komikus untuk menunjukkan ke-Indonesia-an karya mereka belum terlihat sama sekali. Jikapun ada, itu masih dalam jumlah yang sedikit.

Di sisi lain, jika dilihat dari sudut sejarah ternyata embrio komik sebetulnya telah ada di Indonesia sejak jaman dahulu dalam wujud Wayang Beber, meskipun sangat disayangkan karena keberadaan wayang beber saat ini sudah mulai tenggelam oleh gempuran produk-produk budaya yang lebih modern dan bertekhnologi. Namun demikian kenyataan bahwa Wayang Beber bisa disebut sebagai embrio komik ini sebetulnya merupakan berita yang menggembirakan karena hal ini seperti memicu terpancangnya tonggak komik Indonesia untuk memulai kembali memiliki ciri khas dan kebanggan sendiri yang sarat nilai dan visual lokal dalam representasinya di hadapan masyarakat. Sehingga dengan demikian perlu adanya upaya-upaya yang berkelanjutan untuk mengangkat komik ini agar lebih maju daripada sebelumnya.

Dalam konteks masa kini model pagelaran tradisi seperti halnya Wayang Beber sudah kurang menarik, terlebih lagi bagi audiens yang tidak memahami bahasa Jawa yang dipakai sang dalang dalam menuturkan cerita. Disamping itu gambar diam yang sekitar 10 sampai 15 menit dinarasikan oleh dalang terasa monoton. Sehingga kemungkinan hal inilah salah satu faktor yang menyebabkan Wayang Beber ini kurang mendapat perhatian audiens atau masyarakat terutama generasi muda. Pada sisi yang lain kondisi Wayang Beber yang asli sekarang sangat riskan jika dipagelarkan kembali karena akan menimbulkan kerusakan baru yang lebih parah. Sehingga perlu upaya baru yang harus dilakukan untuk lebih mengenalkan wayang ini kehadapan masyarakat dengan presentasi atau media show off yang menarik dan sedang popular saat ini.

Merujuk pada penjelasan sebelumnya, bahwa mengingat Wayang Beber masih ada hubungan dengan dunia komik maka penulis membuat kolaborasi dua bentuk seni yang luar biasa tersebut yaitu komik dengan Wayang Beber. Bentuk kolaborasi tersebut adalah dengan menampilkan Wayang Beber Pacitan lakon Jaka Kembang Kuning gulungan pertama yang terdiri dari empat panel atau pejagong itu dalam format Motion Comic. Motion Comic Wayang Beber Pacitan lakon Jaka Kembang Kuning ini tercipta sebagai wujud penghargaan kepada Wayang Beber atas sumbangsihnya dalam dunia seni rupa terutama sumbangsih Wayang Beber terhadap komik. Disamping itu sebagai wujud pelestarian eksistensi wayang ini agar lebih dikenal di masyarakat luas. Sehingga merujuk hal tersebut di atas maka ada dua aspek novelty dalam karya ini, yaitu pertama aspek penampilan visual dan yang kedua aspek 
media show off-nya ketika dipresentasikan ke hadapan masyarakat.

Adapun proses pembuatan karya ini meliputi beberapa tahap yaitu tahap persiapan dan tahap penciptaan. Tahap persiapan lebih kepada mencari materi dokumentasi sekaligus literatur pendukung dan wawancara. Tahap ini dengan mendatangi langsung lokasi dimana Wayang Beber tersebut berada yaitu di dusun Kedompol Karangtalun Pacitan. Selain mengetahui lokasi dimana wayang tersebut berada serta melihat bentuk asli dari wayang tersebut juga kedatangan ke lokasi juga untuk melakukan wawancara kepada pemilik dan sekaligus dalang dari wayang tersebut.

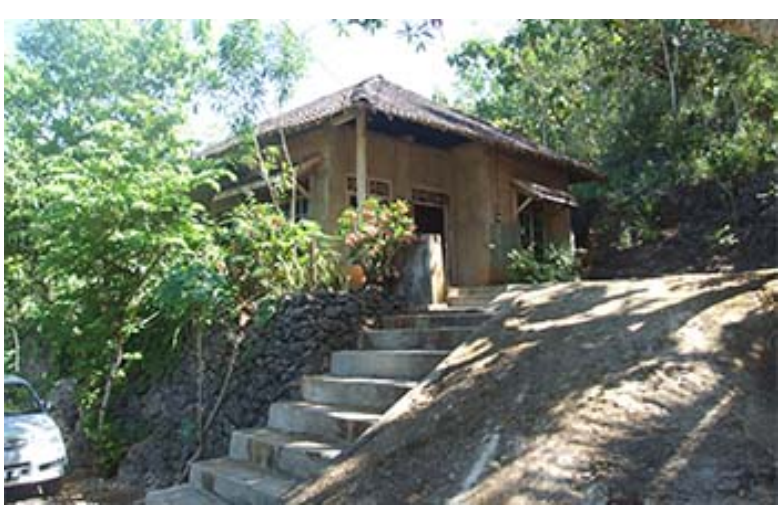

Gambar 2 Foto rumah dimana Wayang Beber Jaka Kembang Kuning berada

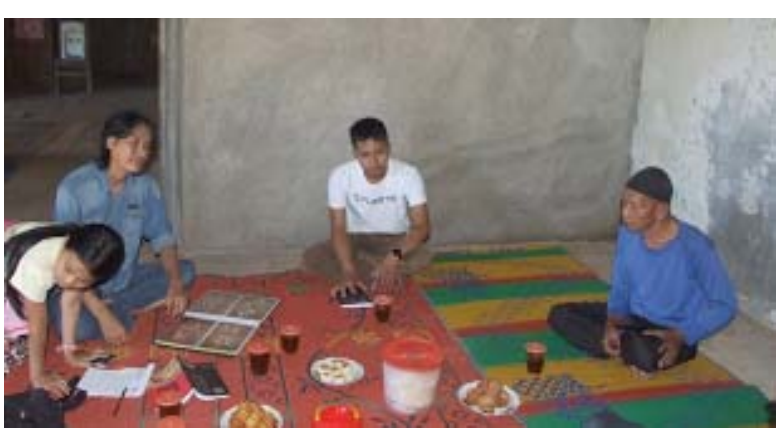

Gambar 3 Wawancara dengan pemilik dan dalang Wayang Beber
Tahap penciptaan merupakan tahap dimana karya ini dibuat yang dimulai dari pembuatan synopsis dari gulungan pertama Wayang Beber Pacitan lakon Jaka Kembang Kuning, dari synopsis kemudian dibuatlah storyline sebagai acuan pembuatan animasi. Setelah itu proses sket dilakukan, kemudian inking, pewarnaan, pembuatan materi animasi, timeline alur animasi, pemberian sound sampai finishing dan rendering. Dalam tahap ini diperlukan ketelitian dan pengaturan material animasi yang benarbenar ketat mengingat proses animasi dengan timeline jika ada satu kesalahan maka akan mengubah semua format yang sudah dibuat.

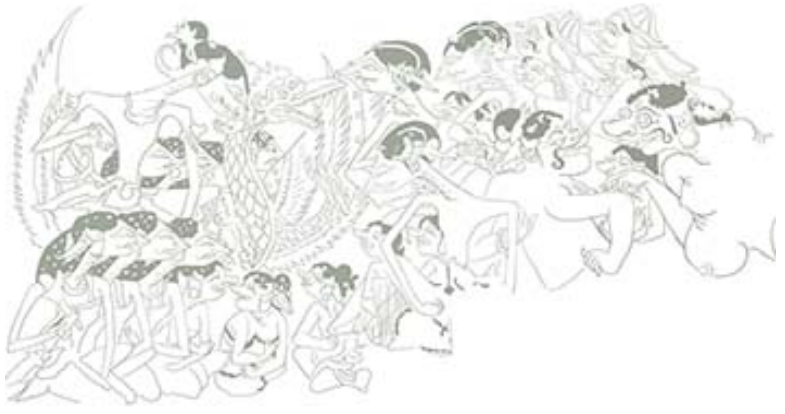

Gambar 4 Sket Wayang Beber Jaka Kembang Kuning

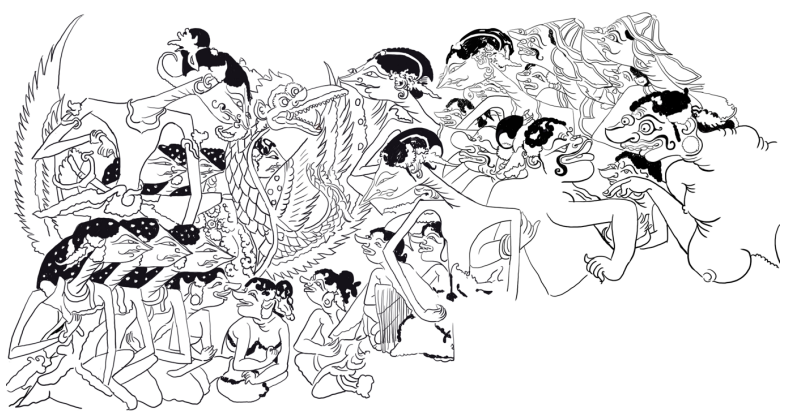

Gambar 5 Inking Wayang Beber Jaka Kembang Kuning 


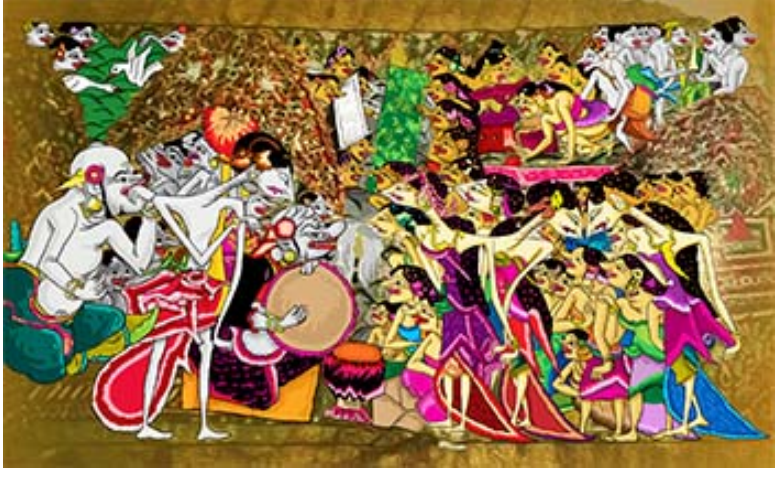

Gambar 6 Pewarnaan Wayang Beber Jaka Kembang Kuning

\section{SENDIKA GUSTI PRABU}

Gambar 7 Balon teks
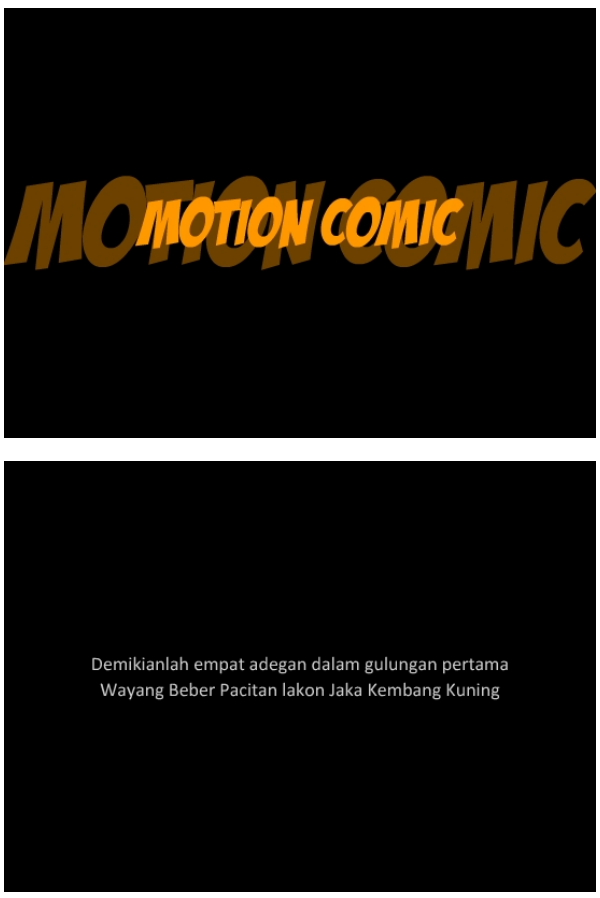

Gambar 8 Animasi opening dan closing

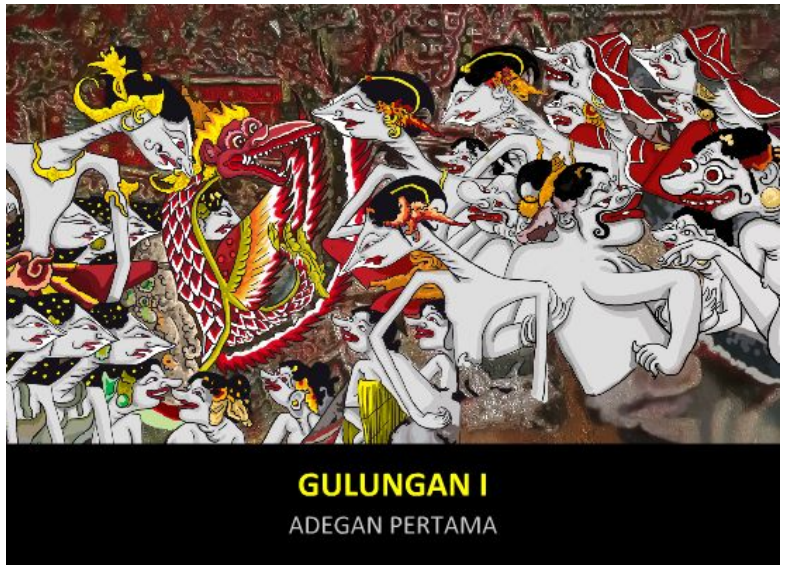

Gambar 9 Caption dalam animasi

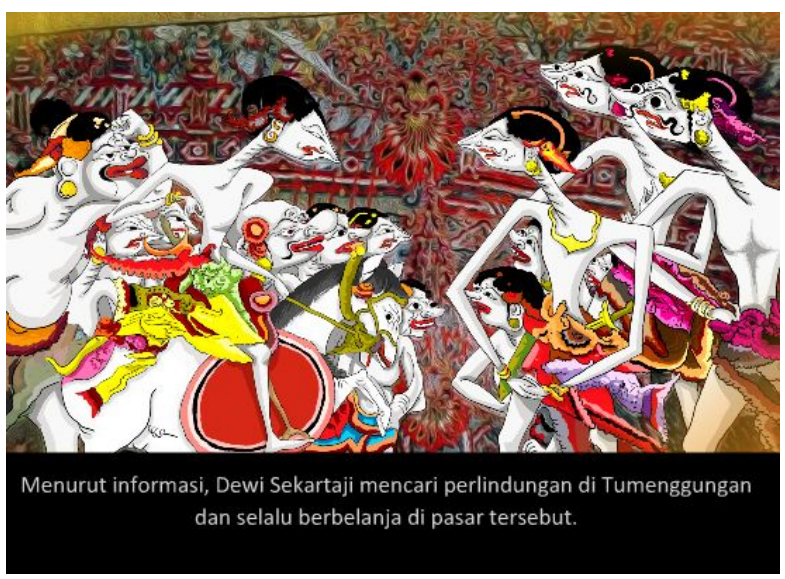

Gambar 10 Caption dalam animasi

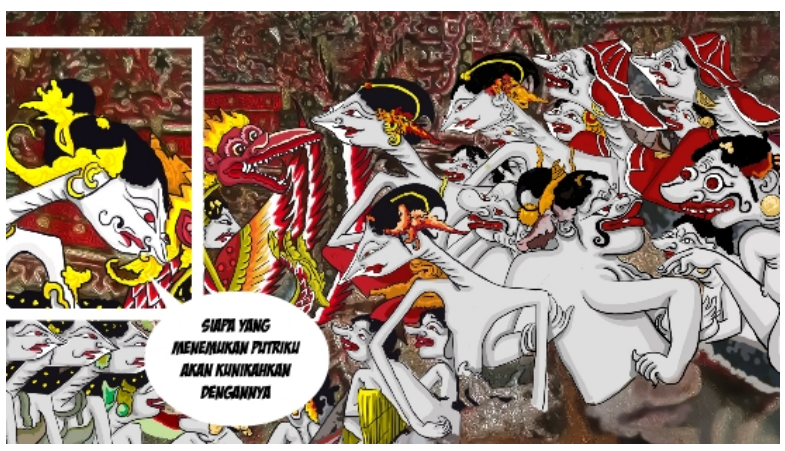

Gambar 11 Balon teks dalam animasi

\section{KESIMPULAN}

Proses penciptaan motion comic Jaka Kembang Kuning memerlukan ketekunan yang ekstra. Hal ini disebabkan karena karakter visual wayang yang terdapat dalam 
Wayang Beber tersebut sangat rumit dan unik, tidak seperti gambar-gambar yang ada saat ini. Sehingga dengan demikian perlu hati-hati, cermat dan teliti dalam menggarap Wayang ini. Selain itu karena usia wayang ini yang sudah ratusan tahun maka garis outline atau kontur sudah tidak begitu jelas. Bahkan warna yang ada sudah memudar. Hal ini menyulitkan sekali untuk membuat duplikasi warna maupun garis kontur yang sangat mirip atau serupa sekali dengan yang asli.

Dalam proses penciptaan ini juga, beberapa hal perlu diperhatikan terkait dengan penjadwalan karena bagian atau tahapan yang dilalui memerlukan waktu yang lebih lama disbanding yang lain. Bukan itu saja, model timeline dalam animasi memerlukan manajemen yang lebih detail sehingga tidak mengacaukan runtutan alur animasi yang dibuat.

\section{DAFTAR PUSTAKA}

[1] Achmad, A. Kasim. (1990), Ungkapan Beberapa Bentuk Kesenian Teater, Wayang, dan Tari, Penerbit Direktorat Kesenian Proyek Pengembangan Kesenian Departemen Pendidikan dan Kebudayaan, Jakarta.

[2] Bonneff, Marcel. (1998), Les Bandes Dessinees Indonesiennes atau Komik Indonesia, terjemahan Rahayu S. Hidayat, KPG, Jakarta.

[3] Gumelar, M.S., (20024), Memproduksi Animasi TV Solusi Murah dan Cepat, Penerbit PT Gramedia Widiasarana Indonesia, Jakarta.

[4] Maharsi, Indiria. (2011), Komik Dunia kReatif Tanpa Batas, Kata Buku, Yogyakarta.

[5] Pustaka Wisata Budaya. (1981), Wayang Beber di Gelaran, Departemen
Pendidikan dan Kebudayaan Direktorat Jenderal Kebudayaan, Jakarta. 